\title{
A cystic fibrosis patient with the nonsense mutation G542X and the splice site mutation 1717-1
}

\author{
M Schloesser, S Arleth, U Lenz, R M Bertele, J Reiss
}

\begin{abstract}
A cystic fibrosis patient with the genotype G542X/1717-1 $(G \rightarrow A)$ was identified by DNA sequencing of exon 11 of the CFTR gene. The available molecular and clinical data are presented. This is the first report of a patient with this rare genotype and may serve to improve our understanding of allele interactions.
\end{abstract}

Cystic fibrosis (CF) is a severe, common, autosomal recessive disorder affecting about 1 in 2000 Caucasian newborns. The predominant mutation is a 3 base pair (bp) deletion in exon $10, \Delta \mathrm{F} 508$, which has an overall frequency of $68 \% .^{1}$ The gene product 'cystic fibrosis transmembrane conductance regulator' (CFTR) is thought to affect the chloride transport through the cell membrane. ${ }^{1}$ The model predicts two transmembrane, two ATP binding, and one regulatory domain. As the function of the protein still remains obscure, genotype-phenotype correlations might help in understanding the molecular mechanisms of this disease and might eventually contribute to the development of a therapy.

So far, eight other mutations clustered in exon 11 affecting the first nucleotide binding fold have been described. ${ }^{23}$ Kerem et $a l^{2}$ and Guillermit $e t$ al $l^{4}$ both reported the mutation 1717-1 at the $3^{\prime}$ end of intron 10 among CF chromosomes of Arabic and Celtic origin, respectively. The base change in the dinuc-

Institut für Humangenetik, Universität Göttingen, Gosslerstrasse 12d, D-3400 Göttingen, Germany. M Schloesser, U Lenz, J Reiss

Dr von Haunersches Kinderspital der Universität München, Kinderklinik, Lindwurmstrasse 4, D-8000 München 2, Germany.

S Arleth, RM Bertele

Correspondence to Dr Reiss. leotide sequence $A G$ to $A A$ destroys the acceptor site for correct splicing of the transcript and may result in a truncated protein through exon skipping or the activation of cryptic acceptor sites.

The other mutation, G542X, is one of several nonsense mutations described so far. ${ }^{25}$ The codon for the amino acid glycine 542 (GGA) is mutated to the translational stop codon TGA. Cuppens $e t a l^{6}$ classified the phenotype of a homozygous G542X mutation as mild, but Bal et $a l^{7}$ reported on a moderately severely affected patient homozygous for R553X. We report here on a patient heterozygous for G542X/1717-1 with a less severe form of CF than in homozygous $\Delta F 508$ patients.

\section{Methods}

A total of 64 German cystic fibrosis patients with at least one non- $\Delta \mathrm{F} 508$ chromosome was analysed. Exon 11 was amplified using primers $11 \mathrm{i}-5^{\prime}$ and $11 \mathrm{i}-$ $3^{\prime}$ in 40 cycles $^{3}$ ( 60 seconds at $92^{\circ} \mathrm{C}, 45$ seconds at $35^{\circ} \mathrm{C}, 120$ seconds at $63^{\circ} \mathrm{C}$ ). R553X and G551D were screened for by restriction with HincII and MboI. ${ }^{3}$ PCR products were then subjected to allele specific oligo (ASO) hybridisation specific for the detection of G542X mutations. ${ }^{2}$ Template preparation for sequencing was performed by subjecting $1 \mu \mathrm{l}$ first round PCR products to 25 cycles of asymmetrical PCR (30 seconds at $94^{\circ} \mathrm{C}, 60$ seconds at $50^{\circ} \mathrm{C}$, $120+5$ seconds extension per cycle at $72^{\circ} \mathrm{C}$ ) with 50 pmol $11 \mathrm{i}-5^{\prime}$ and 1 pmol CF11RM (5'-TGTAA AACGACGGCCAGTAAATGCTTGCTAGACC; the underlined part is identical to the M13-21 primer). Sequencing of the reverse strand of exon 11 was done on an automated DNA sequencer (Applied Biosystems, Foster City, CA, USA) using the Taqdye primer protocol and labelled M13-21 primers supplied by the vendor and a modified T7-polymerase (Sequenase, USB) method (J P Faber, personal communication). 


\section{Case report}

The male patient was the first child born to healthy parents of German origin with no family history of CF. At birth, at 38 weeks' gestation, weight and length were $3350 \mathrm{~g}$ and $52 \mathrm{~cm}$, respectively. There was no intestinal obstruction (meconium ileus). Two weeks after birth typical symptoms of CF (frequent diarrhoea, failure to thrive, and coughing) were observed. At the age of 2 months sweat tests were positive with $82 \mathrm{mmol} / \mathrm{l}$ chloride. Frequent fatty stools indicated pancreatic insufficiency. At the age of $2 \frac{1}{2}$ he was in good condition and well nourished. Whereas weight was on the 25 th centile, height was just below the 25th centile. As often found in CF patients, moderate air trapping was diagnosed. Both lungs were equally inflated. No râles or rhonchi were detectable. The abdomen was moderately distended but there was no evidence of hepatosplenomegaly. Taking account of his age of $2 \frac{1}{2}$, we would preliminarily classify this patient as moderately affected.

DNA analysis of exon 10 from the patient and digestion of exon 11 with HincII excluded the $\Delta F 508, R 553 X$, and G551D mutations. Sequencing of exon 11 showed the genotype G542X/1717-1 (figure). The G542X mutation had been inherited from the father and the 1717-1 mutation was of maternal origin. Both mutations segregate with the high risk B haplotype KM19/XV2c 2-1 and therefore contribute to the overrepresentation of the $B$ haplotype on non- $\Delta$ F508 CF chromosomes, as described by Reis et al. ${ }^{8}$ The frequencies for 1717-1 and G542X were 3 and 5 respectively out of 79 non-
$\Delta$ F508 CF chromosomes and thus account for approximately $1 \%$ and $1.5 \%$ of $320 \mathrm{CF}$ chromosomes in our German sample (unpublished data).

\section{Discussion}

Approximately 80 to $85 \%$ of all CF patients suffer from pancreatic insufficiency (PI) owing to homozygosity of so called severe alleles. Assuming HardyWeinberg equilibrium one can calculate the frequency of severe alleles to be 90 to $92 \%$. These include $\Delta \mathrm{F} 508, \Delta \mathrm{I507}, \mathrm{Q} 493 \mathrm{X}, 1717-1, \mathrm{G} 542 \mathrm{X}$, S549I, S549R, G551D, R560T, 3659de1C, W1282X, and R553X. ${ }^{235}$ Kerem et al suggested a model considering the recessive character of the severe allele $\Delta \mathrm{F} 508$ to all mild alleles; $52 \%$ of all PI patients are homozygous for $\Delta \mathrm{F} 508$ and $40 \%$ are compound heterozygotes carrying an unidentified severe allele. ${ }^{9}$ These figures may vary according to ethnic background. Generally, however, homozygous stop codon mutations, although giving rise to PI, lead to mild pulmonary symptoms in the patient. ${ }^{5}$ Guillermit et $a l^{4}$ reported two pancreatic insufficient patients who were compound heterozygotes for $1717-1 / \Delta \mathrm{F} 508$ and $1717-1 /$ non- $\Delta$ F508. Both were considered to have a less severe form of the disease, did not show any signs of meconium ileus at birth, but were infected by Pseudomonas aeruginosa.

These straightforward genetic considerations get obscured by other conflicting reports. Pancreatic sufficiency (PS) owing to putative mild alleles
(A)

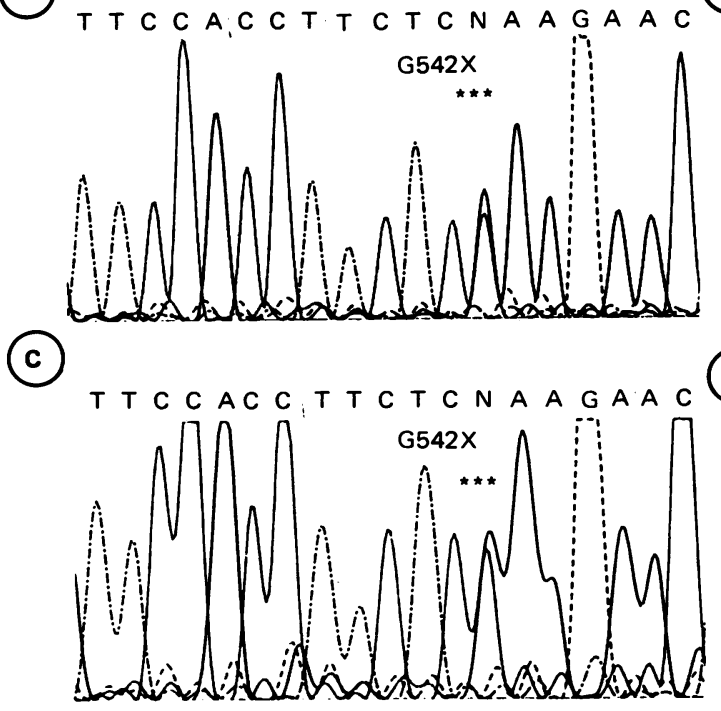

(B)

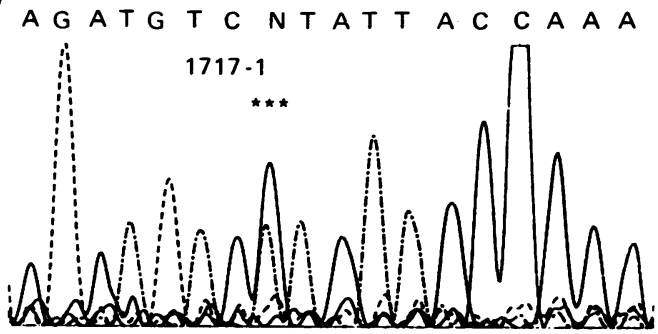

(D)

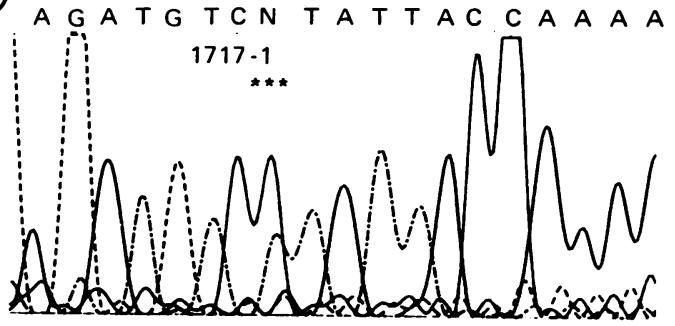

Reverse sequence of exons 11 of the family. Upper panels depict the sequence of paternal ( $A$ ) and maternal (B) DNA and panels $C$ and $D$ show the corresponding parts in the DNA of the patient. Sequence alterations are marked by asterisks. 
including $\mathrm{G} 551 \mathrm{D} /$ non- $\Delta \mathrm{F} 508, \Delta \mathrm{I} 507 / \mathrm{G} 551 \mathrm{D}$ was reported by Curtis et al,,$^{10}$ which is in contrast to the findings of Kerem et al. ${ }^{2}$ Even two homozygous $\Delta$ F508 patients were PS. ${ }^{9}$ Pancreatic insufficiency can be used to assign severe alleles, whereas pancreatic sufficiency may change in patients with 'mild alleles'. Without further case reports on homozygotes and compound heterozygotes the dominant or recessive character of individual alleles cannot be determined.

Taking into account the phenotype found in homozygous $\Delta F 508$ patients, we favour the hypothesis that the CF mRNA of compound heterozygotes for the mutations described above is less stable or yields an unstable protein, which is rapidly degraded. The absence of a mutated regulator of chloride flux may result in a less severe phenotype than the presence of a defective regulator, for example, encoded by a $\Delta F 508$ allele. On the other hand, mutations at the genomic level may be 'bypassed' during transcript processing via exon skipping.

For the time being, definite conclusions cannot be drawn, as these hypotheses can only be tested by a functional activity assay, the demonstration of altered stability or processing of transcript or CFTR protein.

The authors thank Michaela Kulle for technical help, Jacob-Peter Faber and Michael Bormann for providing unpublished sequencing protocols, and Garry R Cutting for advice on the manuscript. This study was supported by grants from the Bundesministerium für Forschung und Technologie.

1 Riordan JR, Rommens JM, Kerem BS, et al. Identification of the cystic fibrosis gene: cloning and characterisation of the complementary DNA. Science 1989;245:1066-73.

2 Kerem BS, Zielenski J, Markiewicz D, et al. Identification of mutations in regions corresponding to the two putative nucleotide (ATP)-binding folds of the cystic fibrosis gene. Proc Natl Acad Sci USA 1990;87:8447-51.

3 Cutting GR, Kasch LM, Rosenstein BJ, et al. A cluster of cystic fibrosis mutations in the first nucleotide-binding fold of the cystic fibrosis conductance regulator protein. Nature 1990;346:366-9.

4 Guillermit H, Fanen P, Ferec C. A 3'splice site consensus sequence mutation in the cystic fibrosis gene. Hum Genet 1990;85:450-3.

5 Cutting GR, Kasch LM, Rosenstein BJ, et al. Two patients with cystic fibrosis, nonsense mutations in each cystic fibrosis gene, and mild pulmonary disease. $N$ Engl $f$ Med 1990; 323:1685-9.

6 Cuppens H, Marynen P, De Boeck C, et al. A child, homozygous for a stop codon in exon 11, shows milder cystic fibrosis symptoms than her heterozygous nephew. $f$ Med Genet 1990;27:717-9.

7 Bal J, Stuhrmann M, Schloesser M, Schmidtke J, Reiss J. A cystic fibrosis patient homozygous for the nonsense mutation R553X. ₹ Med Genet 1991;28:715-7.

8 Reis A, Bremer S, Schloesser M, et al. Distribution patterns of the $\triangle$ F508 mutation in the CFTR gene on CF-linked marker haplotypes in the German population. Hum Genet 1990; 85:421-3.

9 Kerem E, Corey M, Kerem BS, et al. The relation between genotype and phenotype in cystic fibrosis - analysis of the most common mutation ( $\Delta \mathrm{F} 508)$. N Engl f Med 1990; 323:1517-22.

10 Curtis A, Nelson R, Porteous M, Burn J, Bhattacharya SS. Association of less common cystic fibrosis mutations with a mild phenotype. $\mathcal{F}$ Med Genet 1991;28:34-7. 